Artigo Original

\title{
Metodologia para estruturação de hipertexto aplicado ao ensino de enfermagem*
}

\author{
Methodology for the development of bypertext software in nursing education \\ Metodología para la estructuración del bipertexto aplicado a la enseñanza de enfermería
}

Karen Cardoso Caetano ${ }^{1}$, Heloísa Helena Ciqueto Peres ${ }^{2}$

\section{RESUMO}

Objetivo: Descrever a organização de hipertexto sobre Tomada de Decisão em Enfermagem a partir da Técnica de Modelagem de Aplicações Hipermídia - Hypermedia Modeling Technique (HMT) e a Taxonomia de Bloom para nortear os objetivos educacionais. Métodos: Consistiu em cinco etapas: Análise e Planejamento, Modelagem, Implementação, Avaliação, Manutenção e Distribuição. Resultados: A aplicação do HMT auxiliou na classificação das categorias e classes dos objetos e nas associações semânticas, definindo a navegabilidade com menor risco de desorientação do usuário. Conclusão: A modelagem e a definição dos objetivos educacionais contribuíram para alcançar melhores resultados, tanto na elaboração do aplicativo, como na forma de sua utilização no ensino de enfermagem.

Descritores: Educação em enfermagem; Informática médica; Tecnologia educacional; Hipermídia

\begin{abstract}
Objective: To describe the development of hypertext organization to facilitate nursing education and nurse's decision-making process. Methods: Hypermedia Modeling Technique (HMT) and Bloom's Taxonomy of Educational Objectives was used in this five-stage study. The five stages of the study consisted of Analysis and Planning, Modeling, Implementation, Evaluation, Maintenance and Distribution. Results: HMT was useful to categorize and classify objects and to determine their semantic associations, and to define navigability that minimizes users' disorientation. Conclusion: Modeling and definition of educational objectives contributed to the development of the hypertext software and its utilization in nursing education.
\end{abstract}

keywords: Education, nursing; Medical informatics; Educational technology; Hypermedia

\section{RESUMEN}

Objetivo: Describir la organización del hipertexto sobre la Toma de Decisión en Enfermería a partir de la Técnica del Modelado de Aplicaciones Hipermedia - Hypermedia Modeling Technique (HMT) y la Taxonomía de Bloom para dirigir los objetivos educacionales. Métodos: Consistió de cinco etapas: Análisis y Planificación, Modelado, Implementación, Evaluación, Manutención y Distribución. Resultados: La aplicación del HMT ayudó en la clasificación de las categorías y clases de los objetos y en las asociaciones semánticas, definiendo la navegabilidad con menor riesgo de desorientación del usuario. Conclusión: El modelado y la definición de los objetivos educacionales contribuyeron para alcanzar mejores resultados, tanto en la elaboración del aplicativo, como en la forma de su utilización en la enseñanza de enfermería.

Descriptores: Educación en enfermería; Informática médica; Tecnología educativa; Hipermedia

\footnotetext{
*Trabalho extraído da dissertação de Mestrado apresentado na Escola de Enfermagem da Universidade de São Paulo - USP - São Paulo (SP), Brasil.

1 Mestre em Enfermagem pela Escola de Enfermagem da Universidade de São Paulo - USP - São Paulo (SP), Brasil.

${ }^{2}$ Doutora em Enfermagem do Departamento de Orientação Profissional da Escola de Enfermagem da Universidade de São Paulo - USP - São Paulo (SP), Brasil.
} 


\section{INTRODUÇÃO}

A busca pela comunicação e transmissão da informação remonta à época em que os seres humanos desenvolveram a fala como principal forma de comunicação e de transmissão de conhecimento ancestral. Antes do aparecimento da escrita, o uso da comunicação oral foi utilizado em diversas culturas antigas, sendo dependente da memória coletiva como instrumento para armazenar todo o conhecimento vindo dos antepassados ${ }^{(1)}$.

No mundo atual, com a crescente informatização, a sociedade acabou por transformar-se na Sociedade da Informação, pela possibilidade de ter qualquer informação em formato digital. O aparecimento do computador, a sua popularização (Personal Computer "PC") e a Internet contribuíram com essa mudança, transformando o mundo em uma sociedade global interconectada ${ }^{(2-3)}$.

As Tecnologias da Informação e Comunicação introduziram, dessa forma, uma gama de possibilidades. As Tecnologias da Informação são "os processos de produção, armazenamento, recuperação, consumo e reutilização de informações dinâmicas e em constante atualização e envolvem a digitalização de textos, imagens, sons e movimentos". As Tecnologias da Comunicação referem-se aos: "processos de transmissão de dados através de dispositivos técnicos, como fios elétricos, circuitos eletrônicos, fibras e discos óticos"(3).

Assim, a digitalização das comunicações (transmissão e recepção de dados, voz, imagens, etc.) e dos conteúdos (livros, filmes, pinturas, fotografias, música, etc.) faz com que as mídias fiquem disponíveis facilmente e em diversos formatos.

As novas tecnologias permitiram, então, as alterações no formato e organização de textos e livros que puderam ser desenvolvidos em formato de hipertexto. Deste modo, os textos puderam aproveitar todos os recursos de multimídia atualmente disponíveis ${ }^{(2)}$.

O hipertexto surgiu na forma impressa de organização dos livros por meio de sumários, notas de rodapé e comentários para auxiliar o leitor a explorar o objeto de leitura de forma mais focada à sua necessidade. É considerado "um conjunto de nós ligados por conexões. Os nós podem ser palavras, páginas, imagens, gráficos, ou parte de gráficos, seqüências sonoras, documentos complexos que podem, eles mesmos, ser hipertextos", e a estrutura seria caracteristicamente em forma de "estrela, de modo reticular" e não-linear ${ }^{(4)}$.

Ao navegar no hipertexto, o usuário explora um grande mapa de forma fracionada, auxiliado por representações de comandos podendo ser considerado também um "tipo de programa para a organização de conhecimentos ou dados, a aquisição de informações e a comunicação", e por meio dessas representações como, por exemplo, menus e botões interativos, há o acesso à estrutura das informações de forma intuitiva ${ }^{(4)}$.
Pela própria estrutura do hipertexto, caracterizado pelas conexões e nós, faz-se necessário organizá-lo e estruturálo de forma a facilitar a navegação do usuário com o objetivo de evitar desorientá-lo, produzir excesso de informação durante esse processo, ou não proporcionar a profundidade necessária ao assunto pesquisado. As interfaces com excesso de estímulos visuais e sonoros também podem contribuir para essa desorientação ${ }^{(1)}$.

$\mathrm{Na}$ organização de um hipertexto com propósito educacional, devem ser observados alguns cuidados específicos para que alcance seus objetivos de aprendizagem. Dessa forma devem ser observados: a) Tipo de usuário a que se destina; b) Familiarização do usuário ao conteúdo do ambiente virtual a ser projetado; c) Organização de fluxograma ${ }^{(1)}$. Todos esses aspectos organizacionais evitam alguns problemas no qual o usuário: "não sabe onde está, não sabe como navegar para outro lugar, não sabe de onde veio, e não sabe o que pode ser visto a partir de um determinado ponto"(5).

Analisando sob o aspecto da utilização educacional, o hipertexto é: "multimídia interativa, graças à sua dimensão reticular ou não linear" e "favorece uma atitude exploratória, ou mesmo lúdica, face ao material a ser assimilado"(4).

No ensino de enfermagem a utilização do hipertexto pode ser feita por estudantes de enfermagem, para tirarem dúvidas sobre terminologia científica e termos técnicos e em cenários clínicos complexos, fazendo link entre os conhecimentos teóricos e a aplicação em estudos de caso, auxiliando o aluno a resolver problemas reais ${ }^{(6)}$.

$\mathrm{O}$ uso de hipertextos também tem um imenso potencial para profissionais que trabalham no cuidado direto ao paciente, sendo empregado como um meio rápido de acesso às informações clínicas e orientações sobre a assistência de enfermagem.

Assim, a adoção do hipertexto para a tomada de decisão em enfermagem reveste-se de suma importância ao ser abordado em um contexto de aprendizado diferenciado. Esta é uma temática que permeia toda a formação do enfermeiro e não pode ser um conteúdo simplesmente decorado, mas ao contrário, deve ser abordado de forma interativa, estimulando o aluno ao aprendizado e à construção de novos conhecimentos.

Nessa perspectiva, a proposta deste artigo foi descrever a organização de um hipertexto, sobre a temática da tomada de decisão, tomando como referencial, a Técnica de Modelagem de Aplicações (Hipermídia-Hypermedia Modeling Technique) ${ }^{(5,7)}$ e o design e organização do hipertexto ${ }^{(1)}$.

\section{Etapas do desenvolvimento do hipertexto}

A proposta metodológica de organização do hipertexto sobre tomada de decisão seguiu cinco etapas ${ }^{(7)}$ : Análise e planejamento; Modelagem; Implementação; Avaliação e manutenção; e Distribuição. 


\section{Etapa 1: Análise e planejamento}

Nesta fase, são definidos: o tema a ser desenvolvido, os objetivos, o público-alvo e recursos disponíveis.

Tema: A escolha do tema está vinculada ao estudo desenvolvido na dissertação de Mestrado, do Programa de Pós - Graduação da Escola de Enfermagem da Universidade de São Paulo - EEUSP, em que foi construído um ambiente virtual de aprendizagem sobre Tomada de Decisão em Enfermagem, sendo este um dos temas abordados na disciplina de Administração em Enfermagem I, no $4^{\circ}$ semestre do Curso de Graduação da EEUSP.

A disciplina Administração em Enfermagem I é de responsabilidade do Departamento de Orientação Profissional - ENO da EEUSP, constitui um conjunto de disciplinas em que são abordados conteúdos de Administração. Buscando uma abordagem mais contextualizada e voltada à realidade do aluno, optou-se por utilizar como referencial teórico do hipertexto o capítulo do livro de Administração em Enfermagem ${ }^{(8)}$. Para tanto, houve uma reunião com a autora, para explicar os objetivos do trabalho, sendo obtida autorização, por escrito, para o uso do capítulo.

\section{Objetivos}

A elaboração dos objetivos educacionais visa nortear o design instrucional e auxiliar na avaliação do processo ensino-aprendizagem ${ }^{(9)}$.

A proposta de objetivos educacionais expressa uma mudança, manifestada no comportamento, pensamento e ações. Ao definir, de forma clara, o que se espera como resultado do processo de aprendizagem, e quais instrumentos serão utilizados, é possível avaliar o processo de forma mais precisa ${ }^{(10-12)}$.

O processo ensino-aprendizagem desenvolve vários aspectos do indivíduo, que fazem parte da construção do conhecimento. Estes aspectos podem ser divididos em categorias: objetivos cognitivos, objetivos afetivos e objetivos psicomotores ${ }^{(9)}$.

Os objetivos cognitivos envolvem o conhecimento de informações, idéias e conceitos, que são interpretados e compreendidos, e estão vinculados à memória, ao desenvolvimento de capacidades e habilidades intelectuais. Bloom divide o domínio cognitivo em seis níveis de aprendizagem que se sucedem na seguinte ordem: conhecimento, compreensão, aplicação, análise, síntese, $\operatorname{avaliação}^{(11)}$.

Neste trabalho, os objetivos cognitivos que foram definidos são: conhecer os conceitos, definições e fases do processo de tomada de decisão; compreender a importância da inserção do enfermeiro no contexto político-social de tomada de decisão; explicar as fases do processo de tomada de decisão e analisar a situaçãoproblema da realidade objetiva, considerando as dimensões estrutural, singular e particular.

Os objetivos afetivos referem-se aos sentimentos que podem ser experimentados pelos alunos no processo de aprendizado e são expressos em valores, interesses, atitudes, desenvolvimento de apreciações e ajustamento comportamental e disposições emocionais. Os níveis progressivos do domínio afetivo são: organização e caracterização, conceituação, valorização, resposta e recebimento $^{(13)}$.

Desse modo, como objetivos afetivos foram definidos: perceber a importância da utilização de técnicas grupais no processo de tomada de decisão; reconhecer as necessidades individuais e grupais no processo de tomada de decisão; e demonstrar atitude favorável à adoção do processo de tomada de decisão baseada no reconhecimento do contexto político-social.

Os objetivos psicomotores enfatizam atividades de coordenação neuromuscular de materiais e/ou objetos que o indivíduo tenha que desenvolver durante o processo ensino-aprendizagem ${ }^{(12)}$.

Assim, o objetivo psicomotor definido foi: utilizar o hipertexto com desenvoltura.

Público alvo: O público-alvo escolhido foram os alunos do curso de graduação em enfermagem do $4^{\circ}$ semestre, que estavam cursando a disciplina de Administração em Enfermagem I.

A propósito do público-alvo, é importante identificar a acessibilidade e a familiaridade do aluno com o uso do computador, visto que o domínio básico da tecnologia é necessário para que o aluno alcance os objetivos educacionais. A orientação tecnológica do aluno pode ser um objetivo educacional a ser alcançado.

Neste trabalho utilizou-se, como parâmetro do perfil do público alvo da EEUSP, uma pesquisa realizada por uma das docentes que constata acessibilidade e familiaridade com o uso dos computadores ${ }^{(14)}$.

Recursos: Para a concretização do projeto, foram necessários recursos materiais, humanos e financeiros. Para a construção do hipertexto, foi utilizado o Dreamweaver 4.0 for Windows ${ }^{\circledR}$. Este software pode ser considerado um tipo de sistema de autoria, permitindo que o usuário construa páginas web, e insira vários tipos de mídias (som, vídeo, imagem). A pesquisadora não necessitou de recursos humanos de programação, sendo responsável pela construção do hipertexto, tendo contado, porém, com auxílio de outro especialista em Informática em Educação para a modelagem em HMT.

O projeto de Mestrado sobre a construção de ambientes virtuais em enfermagem desenvolvido pela pesquisadora, do qual faz parte o Hipertexto, foi 
contemplado com auxílio financeiro do Ministério da Educação e da Fundação Coordenação de Aperfeiçoamento de Pessoal de Nível Superior - CAPES com o Programa de Apoio à Pesquisa em Educação a Distância - PAPED.

\section{Etapa 2: Técnica de Modelagem ${ }^{(5,7)}$}

Caracterizada pelas aplicações de modelo de objetos, modelo de hiperobjetos, modelo de navegação e modelo de interface.

A técnica de modelagem permite a visualização de um projeto antes de sua construção, auxiliando a definir o domínio de uma aplicação hipermídia, dividindo os nós e conexões, definindo como o usuário fará a navegação, evitando a desorientação e sobrecarga cognitiva, e criando a interface ou a aparência visual do projeto. Dentre os diferentes métodos de modelagem, foi escolhido o Hypermedia Modeling Technique (HMT) para o desenvolvimento do hipertexto.

A forma de tratamento do HMT para as aplicações hipermídia verifica-se por meio do modelo de objetos, modelo de hiperobjetos, modelo de navegação e modelo de interface. Cada um desses modelos tem como propósito depurar a aplicação de forma a torná-los de fácil navegação pelo usuário, evitando a desorientação e o excesso de estímulo cognitivo ${ }^{(8)}$.

\section{O Modelo de Objetos}

O modelo de objetos descreve, essencialmente, os objetos, classificando-os em relação ao domínio ou propriedades similares, atributos dos domínios, relacionamento, associação, e número de ocorrências (cardinalidade) e a generalização e agregação de atributos que pode se visualizado na Figura 1.

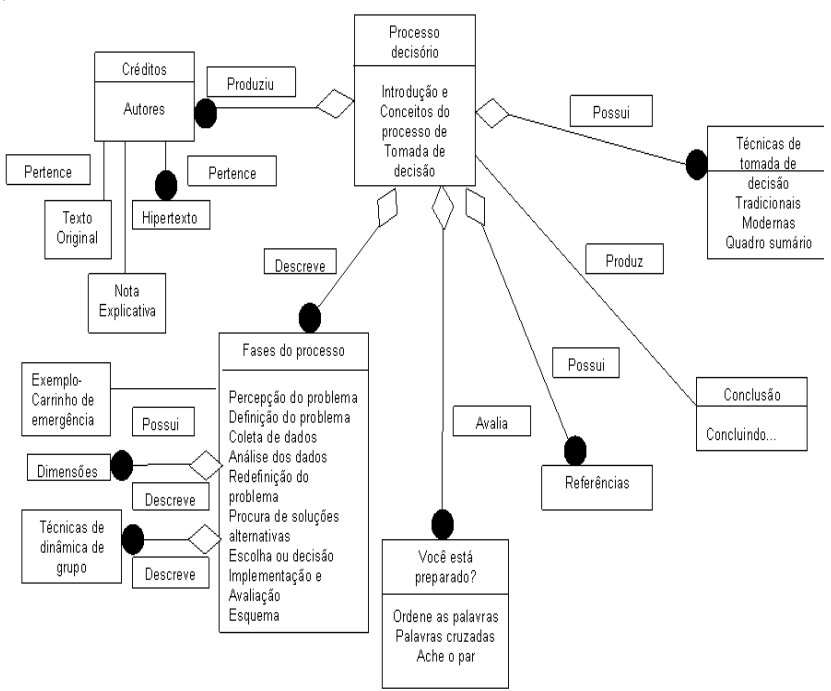

Figura 1 - Modelo de Objetos do hipertexto sobre tomada de decisão.

\section{O Modelo de Hiperobjetos}

Neste modelo, a ênfase encontra-se em: "Definir novas associações e novas classes que estabelecem caminhos desejados, identificar as diferentes mídias que serão utilizadas e as classes abstratas"(8).

\section{O Modelo de Navegação}

No modelo de navegação são definidos os caminhos de acesso aos objetos que são implementados, indicando a relação de uma classe com outra. Portanto, definem como deverão ser organizados e conectados os links, conforme demonstrado na Figura 2.

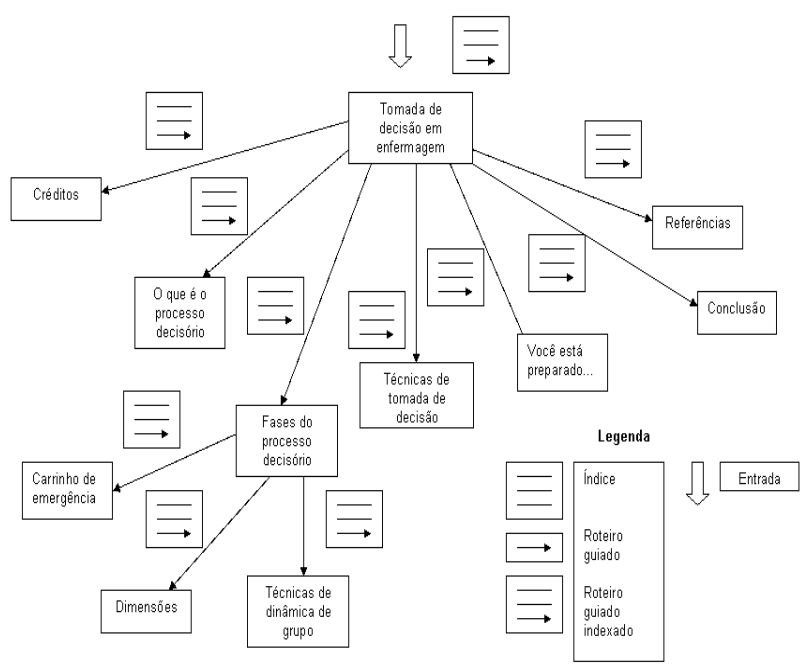

Figura 2 - Modelo de navegação do hipertexto sobre tomada de decisão.

\section{O Modelo de Interface}

No modelo de interface é decidido o aspecto visual da aplicação, podendo ser definido como um "conjunto de elementos que apresentam a organização das informações e as ações do usuário" (5).

A interface da página inicial do hipertexto pode ser exemplificada na Figura 3.

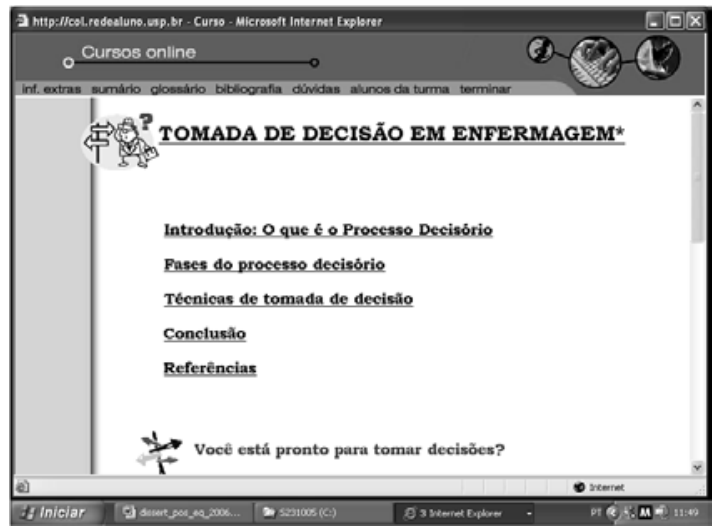

Figura 3 - Página Inicial do Hipertexto. 


\section{Etapa 3: Implementação}

$\mathrm{Na}$ fase de implementação, é recomendada a revisão do texto, verificação de direitos autorais e inserção de créditos e o funcionamento dos nós e links anteriormente planejados. A fase de implementação também compreende a produção ou digitalização das mídias utilizadas na construção do hipertexto, com software específico ${ }^{(8)}$.

\section{Etapa 4: Avaliação e manutenção}

A avaliação do hipertexto significa testar todos os seus links e mídias, para as correções necessárias, relativas a erros de conteúdo e de texto.

\section{Etapa 5: Distribuição}

A distribuição pode ser por CD-ROM ou via rede ou Internet. Neste caso, optou-se por distribuí-lo pela Internet, como parte de um ambiente virtual de aprendizagem sobre tomada de decisão em enfermagem.

\section{CONSIDERAÇÕES FINAIS}

A utilização de um hipertexto digital como estratégia de ensino da temática de tomada de decisão em enfermagem pode ser uma alternativa válida para auxiliar no processo ensino-aprendizagem. Ao transformar um documento escrito em um documento hipermídia, a busca de uma metodologia para modelagem é fundamental para garantir a organização mais adequada do projeto. A aplicação do HMT auxiliou na classificação das categorias e classes dos objetos e nas associações semânticas com as mesmas, definindo uma navegabilidade com menor risco de desorientação pelo usuário. A definição dos objetivos educacionais também contribui para auxiliar o professor a alcançar melhores resultados, tanto na elaboração de um aplicativo, como na forma de utilização no ensino.

\section{REFERÊNCIAS}

1. Portugal C. Hipertexto como instrumento para apresentação de informações em ambiente de aprendizado mediado pela
Internet. Rev Bras Aprend Aberta e a Distância [periódico na Internet]. 2005 [citado 2005 dez 02]; 3(1): [cerca de 7 p.]. Disponível em: <http://www.abed.org.br/publique/cgi/ cgilua.exe/sys/start.htm? UserActiveTemplate $=1$ por\&infoid $=1061 \&$ sid $=69>$.

2. Takahashi T. organizador. Sociedade da informação no Brasil: livro verde. Brasília: Ministério da Ciência e Tecnologia; 2000.

3. Filatro AC. Design instrucional contextualizado: educação e tecnologia. São Paulo: SENAC; 2004.

4. Lévy P. As tecnologias da inteligência: o futuro do pensamento na era da informática. Rio de Janeiro: Editora $34 ; 2000$.

5. Lima JV, Nemetz F, Borges AC. Uma técnica de modelagem de aplicações hipermídia e um exemplo de uso. In: Anais do $15^{\circ}$ Congresso da Sociedade Brasileira de Computação e $21^{\text {a }}$ Conferência Latino-Americana de Informática; 1995; Canela, RS. Canela: SBC; 1995.

6. Guillham D. Using hypertext to facilitate nurse education. Comput Nurs. 1998;16(2):95-8; quiz 99-100.

7. Falkembach GAM. Concepção e desenvolvimento de material educativo digital. Renote- Rev Novas Tecnol Educ [periódico na Internet]. 2005 [citado 2006 maio 21]; 3(1). [cerca de 15 p.]. Disponível em: <http:// www.cinted.ufrgs. br/renote/maio2005/artigos/ a23_materialeducativo.pdf $>$

8. Ciampone MHT. Tomada de decisão em enfermagem. In: Kurcgant P coordenadora. Administração em enfermagem. São Paulo: EPU; 1991. p. 191-206.

9. Bloom BS, Taxonomia dos objetivos educacionais: domínio cognitivo. Porto Alegre: Globo;1973.

10. Chaves LFM, Arias EHL. Elaboração de avaliações: um manual para orientação aos professores do Centro de Ciências da Saúde da UFPA. [texto na Internet]. Belém (PA): Universidade Federal do Pará. Centro de Ciências da Saúde; 2003. [citado 2006 maio 20]. Disponível em: <http://www.ufpa.br/ccs/ manualparaorientacaodeprofessores.pdf $>$

11. Peres HHC, Leite MMJ . Software educacional: objetivos educacionais. Versão II [CD-ROM]. São Paulo: EEUSP; 2000.

12. Teixeira G. Elaboração de objetivos educacionais no ensino superior. [texto na Internet]. [citado 2006 abr 24]. Disponível em: <http:/ /www.serprofessoruniversitário.pro.br/ ler.php?modulo $=16 \&$ texto $=967>$

13. Davies IK. Competency based learning: technology, management, and design. New York : McGraw-Hill; 1973.

14. Peres HHC, Meira KC. Didática em enfermagem mediada pelo computador: avaliação discente. In: Anais do $13^{\circ}$ Simpósio Internacional de Iniciação Científica da USP; 2004; Ribeirão Preto [CD-ROM]. Ribeirão Preto: USP; 2004. 